millennium, but from the dawn of civilization till date, the woman of the patriarchal society of India continues to be oppressed and ill-treated. She is dependent, weak, exploited and faces gender discrimination in every sphere of life. The genderbased violence that threatens the well-being, dignity and rights of women, extends across social, cultural, economic and regional boundaries.

The Supreme Court guidelines on sexual harassment at work place: For the first time, the Court drew upon an international human rights law instrument, the CEDAW to pass a set of guidelines. The Court defined sexual harassment at work place as any unwelcome gesture, behavior, words or advances that are sexual in nature. "It shall be the duty of the employer or other responsible persons in work places or other institutions to prevent or deter the commission of acts of sexual harassment and to provide the procedures for the resolution, settlement or prosecution of acts, of sexual harassment by taking all steps required."

\section{Role of ICT}

In the age of the "information society", information and communication technologies (ICTs) and the Internet play a big role in the battle against sexual abuse and violence against women, both as tools to curb such violence, but at times also as new spaces for harassment and abuse. While ICTs and Internet can pose a risk to women and girls, they can also offer new, innovative ways to battle violence against women and to provide women and girls with more protection, more security and more independence.

Women safety has become the utmost priority of the Indian government considering the increasing cases of crime against women.

There are various safety apps present on the play store designed for the protection and security of women. The basics of most apps are similar - a user-decided list of emergency contacts to alert, and transmission of GPS-determined location - but the newer ones are easier to use, almost intuitive.

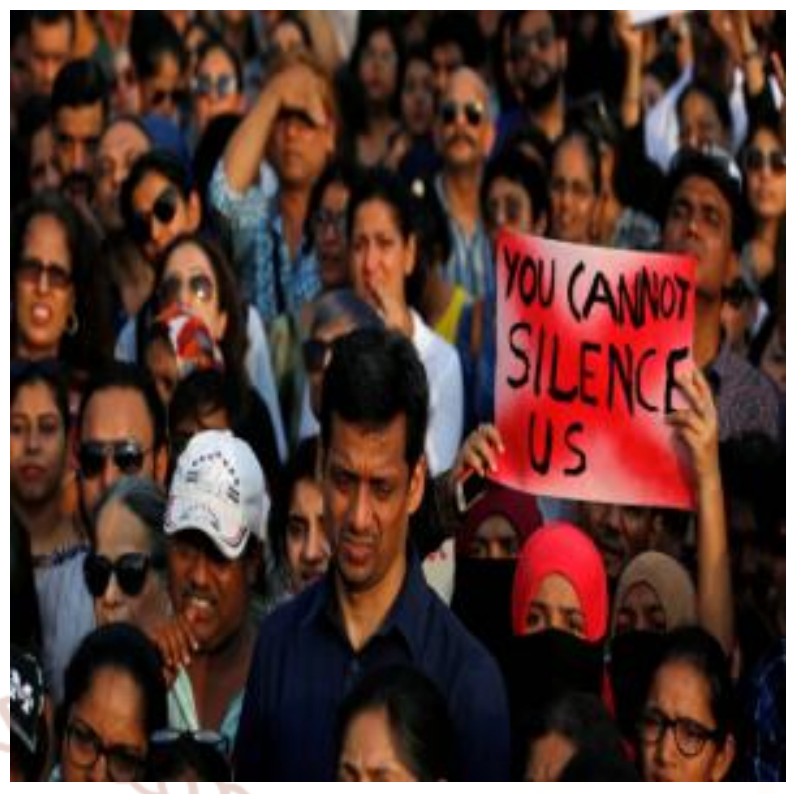

Safety Apps

Safetipin: The app is designed keeping in mind the concept of personal safety. It incorporates all the essential features such as GPS tracking, emergency contact numbers, directions to safe locations etc. The app also pins the safe areas along with their safety scores to go at the time of any problem. It also enables the users to pin unsafe areas and help others. Safetipin is available in Hindi, Bahasa and Spanish, besides English.

The Raksha: This app is designed to ensure that women stay safe always. The app comes equipped with a button, which will send alerts to your loved ones with your location in a situation of distress. You can select the contacts, which will be able to see your location. Moreover, if the app is switched off and is not working then also you will be able to send alerts by simply pressing the volume key for three seconds.

The Himaat: It is a free safety app recommend for women by the Delhi Police. In order to use the app, the user has to register at the Delhi Police website. Once the registration is complete the user will receive an OTP, which has to be entered at the time of completing the app configuration. In a problematic situation if the user raises the SOS alert from the app, the location information and audio video will be directly transmitted to the Delhi Police control room following which the police will reach the location.

Women safety: The Women Safety app that will inform and update your dear ones if you are stuck 
in an unsafe place. It will send all the details related to your location with just a tap of a button. The app will send an SMS to a preconfigured number along with your location and a link of Google Maps. The app will also click two pictures with the front and rear camera, which are directly uploaded to the server. The Women safety app comprises of three coloured buttons based on the seriousness of a situation. So, you can tap the one you want depending on your situation.

$>$ Smart: The Smart24x7 app is supported by the various states' police just to ensure the safety of women and senior citizens. The app sends panic alerts to emergency contacts in a problematic situation. It also records voices and also takes photographs during the panic situation and transfers these to the police as well. It also has call centre support, which will track down the primary movements of the user. Users just need to press the panic button and select the type of service required and then finally click on submit.

Shake2Safety: The Shake2Safety app is the easiest to use. The user just needs to shake their smartphone or just press the power button four times to send an SOS text or call to the registered numbers. It works with the locked screen on and even without an internet connection. Moreover, the users will also have the ability to activate or deactivate the option of shaking the device to send an alert. The app can also be used in case of an accident, harassment, robbery or any natural calamities.

bSafe: The bSafe app ensures the safety and security of women. It allows contacts follow you through a live GPS trail and also set a timed alarm which goes off if you haven't 'checked in'. Moreover, it will also make your phone ring with a fake call and also notifies the emergency contacts with the location, video and even siren. Along with this, there is also a Guardian Alert button, which will immediately tell your friends or family members with the GPS location and video at the time of distress.

Eyewatch: The Railway Protection Force (RPF), Western Railway, in collaboration with Eyewatch Technologies Pvt. Limited, launched the app to report acts of sexual harassment against women at the earliest. Women commuters have used the app to get speedy response to a panic call.

Circle of 6 (White House's “Apps Against Abuse"): This smart phone app is an example of an innovative use of technology to provide women with tools to protect themselves from sexual assault and rape. Circle of 6, released in March 2012, allows users to program six friends into a "circle", and has pre-programmed SMS messages, such as "call and pretend you need me. I need an interruption" or "come and get me, I need help getting home safely" that can easily be sent to the people programmed into the circle. The user's location is also sent to the circle through GPS technology, and the app has sexual assault, rape and abuse hotline numbers pre-programmed, with the user being able to add an additional one of their choice.

Fight Back" was developed to protect women against "eve teasing", term used in India to describe men's unwanted attention towards women ranging from uncomfortable and threatening staring to unwanted physical contact. Fight Back sends the user's location via GPS to pre-programmed contacts along with an SOS message with one push of a button, and it can also be linked to Facebook.

Harass Map: It was developed in Egypt to receive anonymous reports of sexual harassment through SMS. All the reports are updated on a map in real-time, which gives a viewer an overview of where possible "harassment hotspots" and dangerous areas are located. Not only does it offer women the ability to avoid places where harassment seems to be common, but it can also provide authorities important data on areas where women's harassment is concentrated and security measures need to be increased.

\section{Technology ahead:}

Presently, whatever apps are available or in use, all are based on the push technology, which require women intervention in case of incidents. The ICT should develop technology, which may sense and summon in case of eventuality. A app developed by CDAC named M-Kavach, which is used for smartphone protection. M-Kavach comes as an effort to deal with unauthorized access to a smartphone's resources like Wi-Fi, Camera, Bluetooth etc. The app 
comes with features which restrict access to critical applications like Mobile wallets, Social media apps and more. It also allows users to block unwanted calls and SMS.

Another app developed by a Bangalore based company for medical emergency is a reactive app, which send the alerts to registered destination in case of an emergency. Safezy $24 X 7$ helpline in fall, medical emergency, safety need of elderly, disabled, Alzheimer/dementia (memory loss), cardiac, epilepsy(fall), Parkinson (tremor), and heart patient. Safezy app or Wear phone alerts automatically with location to hospital, caregiver, police and relative via call/SMS/Email in case of emergency. Most of the functionality of this app is based on the pull technology.

The functionality of both the apps may be combined and a new app may be developed for women safety, which may work with waerphone technology as well as work on the basis of push and pull technology. The new technology may ensure the safety of the women in such situation where women is not in a position to initiate the alert. Another advantage of this technology is that it may work on any phone, not necessarily the smartphone.

\section{Conclusion:}

There are technologies, which may generate and deliver alerts to the concerned agencies but ultimate result depends upon the enforcement. In the light of above information, it may be concluded that:

$>$ Violence against women is a social, economic, developmental, legal, educational, human rights, and health (physical and mental) issue.
$>$ It is a preventable cause of morbidity and mortality in women

> The relationship between violence against women and mental illness has not been adequately explored.

$>$ Application of laws related to violence in the setting of mental illness is difficult

$>$ Despite the social and religious sanctions against it in all cultures, it has continued.

$>$ Responses by communities, religious institutions, government (various commissions), international conventions, stringent legislations and penal measures have failed miserably in containing the menace.

ICT may help at large scale, subject change in the perception of government, administration and enforcement agencies

\section{References:}

1. http://indianexpress.com/article/cities/mumbai/life -on-the-ocal-mobile-app-to-check-crimes-againstwomen-tests-waters-4980245/ (Accessed on 06.06.2018)

2. http://safezy.easym $2 \mathrm{~m} . \mathrm{in} /$

3. https://timesofindia.indiatimes.com/tech/7-bestwomen-safety-apps/women-

safety/photostory/51285634.cms (Accessed on 06.06.2018)

4. https://www.girlsglobe.org/2013/05/02/preventing -violence-against-women-through-mobile-apps/ (Accessed on 06.06.2018)

5. Mary Astel 1668-1731: Some Reflections upon Marriage (1706 ed.)

6. https://www.ncbi.nlm.nih.gov/pmc/articles/PMC4 462781/ (Accessed on 06.06.2018) 